\title{
Investigation the effect of Graphene on The Morphology, Mechanical and Thermal properties of PLA/PMMA Blends
}

\author{
Azin Paydayesh ${ }^{1}$, Ahmad Aref Azar ${ }^{1,2,}$, Azam Jalali Arani ${ }^{1,2}$
}

1. Amir Kabir University of Technology, Mahshahr Campus, Mahshahr, I.R.Iran

2. Polymer Engineering Department, Amir Kabir University of Technology, Tehran, I.R.Iran

${ }^{*}$ Corresponding author: E-mail address: arefazar@aut.ac.ir; Tel/Fax: +98-21-6454-2430

\begin{abstract}
In this work, Poly Lactic Acid/Poly methyl Methacrylate (PLA/PMMA) blends in various compositions prepared and morphology and properties of these blends was investigated. Moreover, the effect of adding different amounts of Graphene Nanoplatelets (GNP) on the morphology of the blends (by SEM), the interaction of nanopalates with polymer phases (by FTIR) and its effect on the mechanical properties and thermal stability of the samples were examined. The results of the study showed that in different amounts of graphene, these plates were preferentially located in the polymer phases dissimilarly and thus, caused the change of the blend morphology. In addition, measuring the mechanical properties by tensile test and results of thermal analysis by TGA indicated the improvement of thermal stability, modulus and mechanical strength and reduction of the elongation at break of graphene containing blends with increasing the loading of GNP. The changing behavior of the mechanical and thermal properties was proportional to the Graphene localization in blend phases.
\end{abstract}

Key words: Polymer Blends, Graphene Nanoplatelets (GNP), Morphology, Mechanical Properties, Thermal Properties 


\section{Introduction}

In the recent years, environmental contaminations caused via the indiscriminate use of plastic products have become a major concern to protect the environment. One of the ways to solve this problem is using of biodegradable polymers instead of synthetic polymers. Poly lactic acid (PLA) is a biocompatible and biodegradable thermoplastic polymer with properties similar to polyethylene terephthalate (Henton, (2005)) This polymer is very convenient for medical and pharmaceutical, packaging and food applications. Although PLA has good strength and high modulus, it is a brittle polymer with a low toughness and impact strength which is why its use has been limited in other applications. (Yuan, (2009)). Jancar (1999), Zhang (2003), Anderson(2008), Balakrishnan (2012) and Mittal(2012), investigated several methods to improve PLA mechanical properties, such as copolymerization, blending and adding nanoparticle have been considered.

Always, Blending of two polymers has been considered as an economical and easy way to improve the properties of polymers and so far, a lot of studies have been conducted to evaluate the effect of blending on various properties of PLA, for example studies by Teamsinsungvon (2013), Fu (2013), Gui (2013), and Jung (2014). It should be noted that in the polymer blends the properties of the final product depend not only on the intrinsic properties of both phases and the composition of phases but also on morphology and their compatibility. Therefore, examining and controlling the morphology of polymer blends are one of the most fundamental keys in the control and achievement to the favorable properties (Paul(2000)).

On the other hand, in recent years, the polymer nanocomposites have attracted strong attentions to improve the mechanical and thermal properties, electrical conductivity etc. However, the properties of polymer nanocomposites also depend on the interaction of nanoparticle with polymer, the quality of its distribution in the polymer matrix, the amount of nanoparticle and its translocation localization (in the cases that matrix of nanocomposite is a polymer blend) (Mittal(2014)).

Graphen is a natural layered material with one-atom two-dimensional layers of sp2-bonded carbon atoms which are connected together in a hive-like network (Terrones (2011)). Due to its unique structure and properties such as high electrical conductivity, high mechanical strength, high thermal conductivity and good optical properties, it has been highly regarded by scientists and researchers and the after discovery of graphene, numerous studies have been done on the preparation of polymer nanocomposites by graphene and their properties, for examples researches done by Neto (2009) and Allen (2009). In most studies, ( such as Du(2012), Yang(2013) and Liebscher (2013) researches) the considerable improvement in the presence of graphene in these nanocomposites has been observed in properties which cannot be normally achieved [24-27]. However, due to the high tendency of grapheme to form large aggregates, the access to the appropriate distribution of graphene nanoplatelets (GNP) in a polymer matrix has always been an essential challenge.

Recently, Cao (2011), Mohamadi (2012) and Pötschke (2014) have investigated the effect of graphene on the properties of polymer blends.

Because of the remarkable ability of graphene to improve the properties of polymer nanocomposites and its using in polymer blends, in this study, the effect of graphene on the morphology of PLA/PMMA was evaluated and the interaction between graphene and polymer phases were examined. In addition, mechanical properties and thermal stability of the mentioned blends were investigated by adding the different amount of GNP.

\section{Experimental}

\subsection{Materials}

Poly Lactic Acid (PLA, 2003D) was prepared with melt flow index of $6 \mathrm{~g} / 10 \mathrm{~min}$ and $\mathrm{Mw}=$ $246500 \mathrm{~g} / \mathrm{mole}$ from Nature Works LLC Co. Poly methyl Methacrylate (PMMA) (Agryrex 205) was purchased with a melt flow index of $1.8 \mathrm{~g} / 10 \mathrm{~min}$ and $\mathrm{Mw}=90400 \mathrm{~g} / \mathrm{mole}$ from Chimei Co. Graphene Nanoplatelets (GNP) was provided 
with specific surface area of $700 \mathrm{~m}^{2} / \mathrm{g}$ and thickness of about $3 \mathrm{~nm}$ from the internal market. Dimethyl formamide (DMF) and chloroform were purchased as solvent from Daejung Co. Before preparing samples, PLA and PMMA were first dried in the oven at the temperature of $90^{\circ} \mathrm{C}$ for 4 hours and kept in desiccator until use.

\subsection{Sample Preparation}

For preparing the samples, the suspension of graphene was first prepared in chloroform with the concentration of $0.5 \mathrm{~g}$ in $50 \mathrm{ml}$ of chloroform by magnetic stirrer at the room temperature for a day and then sonication for a half an hour. Then, the predetermined amounts of polymers were added and mixed for another day at the room temperature by a high-speed mixer. Next, the prepared solutions were cast in a petri dish to evaporate the solvent during 24 hours. In this way, samples containing different values of graphene were prepared in combination of different percentages of polymers. The composition of the prepared samples with their related codes has been given in Table 1 .

Table 1: Blends and nanocomposite blends composition and their codes

\begin{tabular}{|c|c|c|c|c|c|c|c|c|c|c|c|c|c|c|c|}
\hline 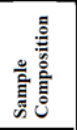 & 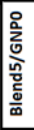 & 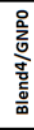 & $\begin{array}{l}\frac{0}{2} \\
\frac{0}{0} \\
\text { m. } \\
\frac{0}{c} \\
\frac{0}{0}\end{array}$ & 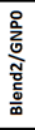 & 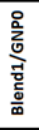 & 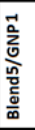 & $\begin{array}{l}\frac{\overrightarrow{0}}{0} \\
\frac{0}{0} \\
\frac{0}{0} \\
\frac{0}{0}\end{array}$ & $\begin{array}{l}\frac{-1}{0} \\
\sum_{0} \\
\frac{m}{c} \\
\frac{c}{c} \\
\frac{\omega}{\infty}\end{array}$ & 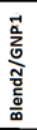 & $\begin{array}{l}\overrightarrow{-1} \\
\frac{\overrightarrow{0}}{0} \\
\frac{7}{0} \\
\frac{0}{0} \\
\frac{0}{0}\end{array}$ & 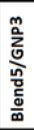 & 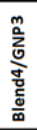 & $\begin{array}{l}\frac{m}{0} \\
\sum_{0} \\
\frac{m}{0} \\
\frac{\tilde{c}}{\tilde{c}} \\
\frac{\omega}{\omega}\end{array}$ & 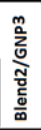 & 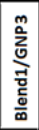 \\
\hline $\begin{array}{c}\text { PLA } \\
\text { (wt. \%) }\end{array}$ & 70 & 60 & 50 & 40 & 30 & 70 & 60 & 50 & 40 & 30 & 70 & 60 & $\mathbf{5 0}$ & 40 & 30 \\
\hline $\begin{array}{l}\text { PMMA } \\
\text { (wt. \%) }\end{array}$ & 30 & 60 & 50 & 60 & 70 & 30 & 40 & $\mathbf{5 0}$ & 60 & 70 & 30 & 40 & $\mathbf{5 0}$ & 60 & 70 \\
\hline $\begin{array}{l}\text { GNP } \\
\text { (phr) }\end{array}$ & 0 & 0 & 0 & 0 & 0 & 1 & 1 & 1 & 1 & 1 & 3 & 3 & 3 & 3 & 3 \\
\hline
\end{tabular}

\subsection{Characterizations}

Raman spectroscopy: Raman spectroscopy was used to identify the structural characteristic of graphene in the range of wave number of $3000-600 \mathrm{~cm}^{-1}$ and the laser wavelength of $532 \mathrm{~nm}$ by FirstGuard, Rigarku instrument.

Fourier Transform Infrared Spectroscopy (FTIR): Fourier Transform Infrared Spectroscopy Nicolet Nexus-870 model equipped with ATR technique was used for investigation of the interaction between graphene nanoplatelets and polymer phases. Measurement was conducted in the range of wave number of $500-4000 \mathrm{~cm}^{-1}$ and based on ten scan for each sample.

Scanning Electron Microscopy (SEM): In order to observe the morphology of samples, SEM (AIS2100, Seron technology Co.) with accelerating voltages of $20 \mathrm{kv}$ was used. For better observing the morphology, the DMF solvent was used to dissolve selectively and etched PMMA phase. Then, samples were coated with a layer of gold to photograph their crosssection.

Tensile Test: The mechanical properties of samples were measured by tensile test at the room temperature and (using 10/M, MTS) according to ASTM D882 and with speed of 50 $\mathrm{mm} / \mathrm{min}$. Tensile strength, modulus and elongation at break of samples were measured and reported for the average of 5 repeats for each sample

Thermal Gravimetric Analysis (TGA): To investigate the thermal stability of samples, Perkin Elmer (USA) TAG was used under a nitrogen atmosphere and with heating rate of $20^{\circ} \mathrm{C}$. The weight of all samples was $5 \pm 0.1 \mathrm{mg}$.

\section{Results and Discussion}

\subsection{Raman spectroscopy}

In order to recognize the structure of used grapheme, Raman spectroscopy (Figure 1) was used. Graphene shows three peaks including Gband in $1580 \mathrm{~cm}^{-1}$, 2D-band in $2700 \mathrm{~cm}^{-1}$ and Dband in $1360 \mathrm{~cm}^{-1}$ in the spectroscopy. Although the Raman spectrum of grapheme is simple and has few characteristic peaks, it contains very useful information for characterize the structure of graphene. According to the spectrum, beside on the position and intensity of G-band and especially the ratio of G-band to 2D-band, the number of layers and thickness of grapheme can be obtained. According to Figure 1, the used grapheme had many layers and graphite like structure.

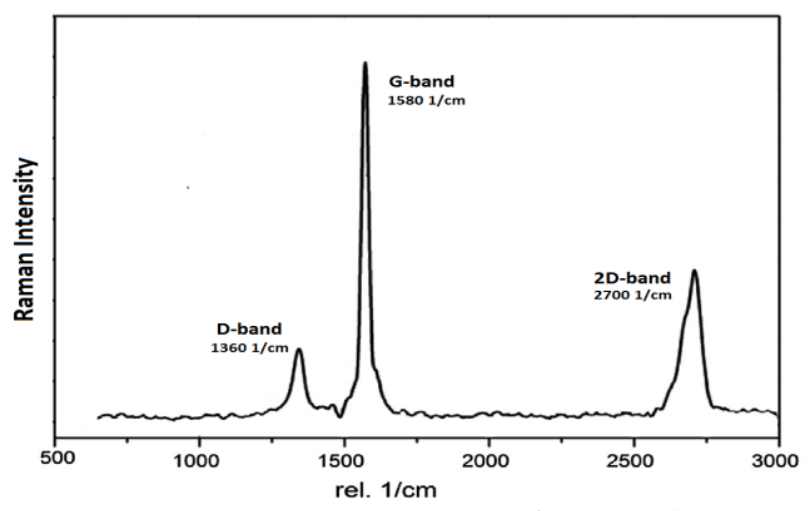

Figure 1 Raman spectrum of the used Graphene Nanoplatelets

\subsection{Morphology}


Figure 2 show the morphology of PLA/PMMA blends without grapheme in the different composition. In these images, the dark areas show the PMMA phase that it etched by DMF. In all samples except for Blend2/GNP0, PLA and PMMA form continuous and dispersed phase, respectively.
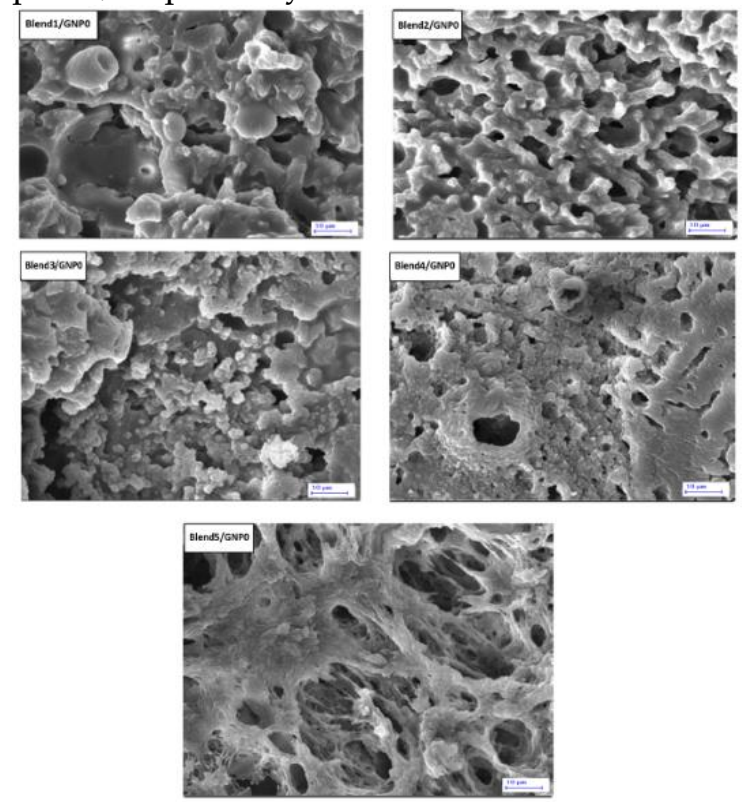

Figure 2. SEM photograph of PLA/PMMA at different composition

In Blend2/GNP0, the co-continuous morphology was observed. Figure 3 and 4 show the morphology of the blends when 1phr and 3 phr graphene were added to them.
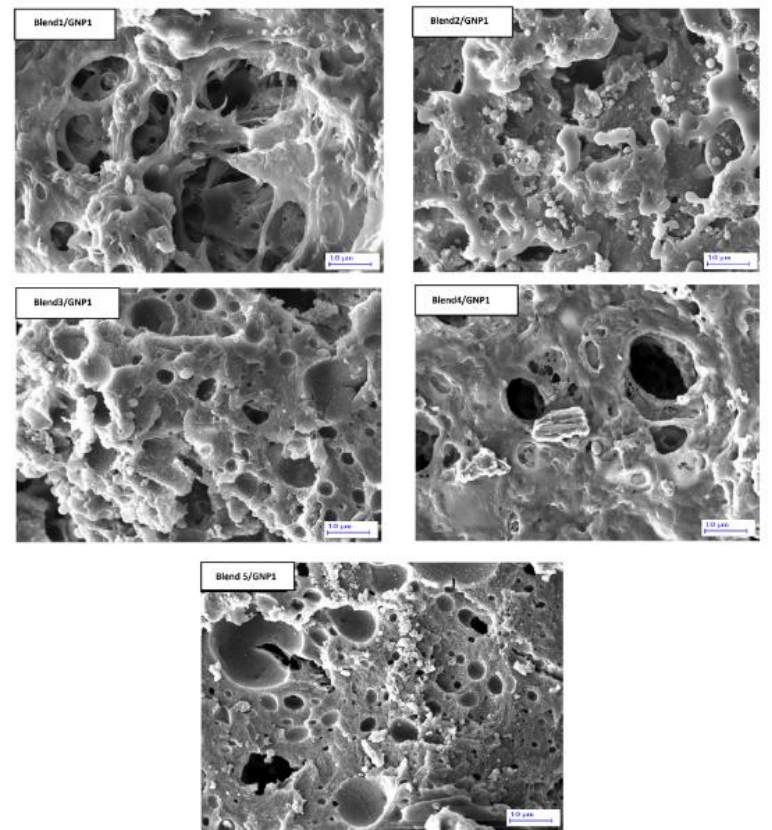

Figure 3. SEM photograph of PLA/PMMA with 1 phr graphen at different composition of blend
It was found that by adding graphene, the morphology of blend changes; however, these changes were different for various amounts of graphene. In addition, the Blend2/GNP0 sample which formed the morphology of co-continuous phases changed by adding graphene to the morphology of sea-island. When 1phr graphene was added, in all samples, the PMMA domains were larger than blend without graphene (Figure 2) but when the amount of grapheme reached to 3phr, droplets of PMMA became smaller and more uniform.

It is well known that in the polymer blends, the smaller and more uniform size and distribution of dispersed phase represent an increase in the compatibility of two polymer phases. It can be stated that only when the amount of grapheme increased to $3 \mathrm{phr}$, the effect of compatibility of GNP was observed.
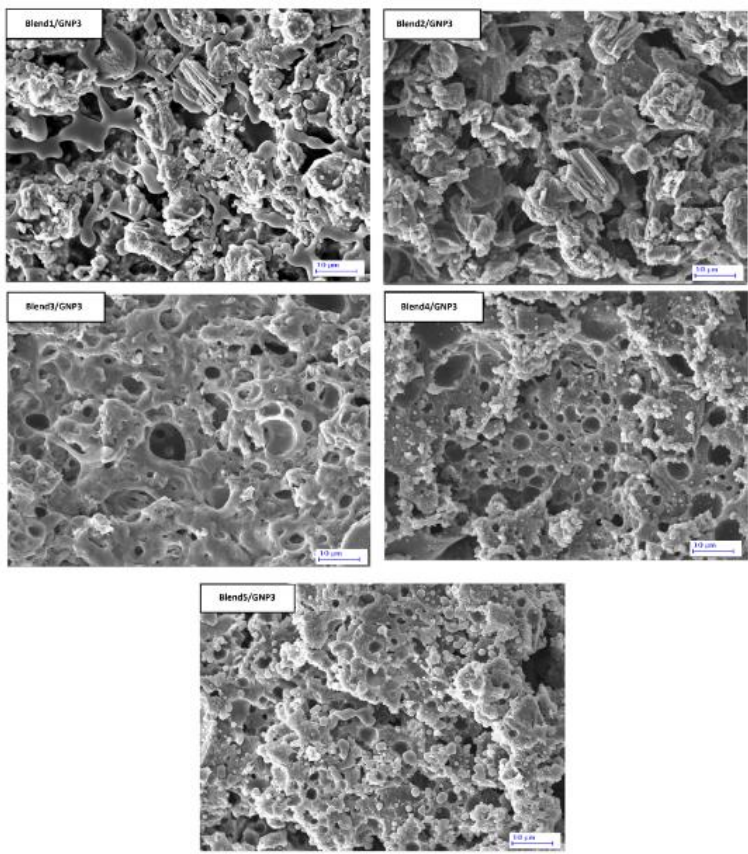

Figure 4. SEM photograph of PLA/PMMA with 3 phr graphen at different composition of blend

\subsection{Fourier Transform Infrared Spectroscopy (FTIR)}

To investigate the interactions between GNP and polymer phases, FTIR-ATR was used.

The infrared spectrum of PMMA compared with PMMA/GNP and Blend3/GNP1 is shown in Figure 5 and the infrared spectrum of PLA and its nanocomposites with graphene and 
Blend3/GNP3 in illustrated in Figure 6. The absorption peak appeared in the infrared spectrum of PMMA and PLA is given in Table 2. For PMMA, the peaks of carbonyl group in 1731 $\mathrm{cm}^{-1}$ transferred into the wave number of 1724 $\mathrm{cm}^{-1}$ in PMMA/GNP. Also, according to what is shown in Figure 6, for PLA containing grapheme, the peak of carbonyl group in PLA in the wave number of $1747 \mathrm{~cm}^{-1}$ shifted to $1744 \mathrm{~cm}^{-}$ 1. The other peaks of PLA spectrum have been appeared almost unchanged in the spectrum of PLA/GNP.

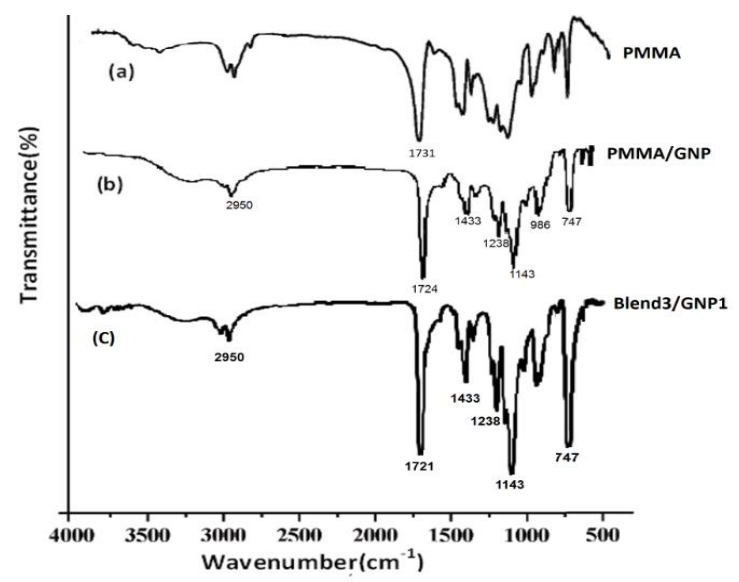

Figure 5: FTIR spectra of PMMA in comparison with nanocomposites and blend nanocomposite

The transmission of the peak of carbonyl group (which is very sensitive to chemical interactions) represents surface adsorption of both polymer phases on Graphene Nanoplatelets. However, it seems that these interactions and surface adsorption with PMMA is stronger than PLA.

Table 2: Absorption peaks of infrared spectrum for PLA and PMMA

\begin{tabular}{|l|l|l|l|}
\hline \multicolumn{2}{|c|}{ PMMA } & \multicolumn{2}{c|}{ PLA } \\
\hline \multicolumn{1}{|c|}{ Absorption peak } & Wave number & \multicolumn{1}{c|}{ Absorption peak } & Wave number \\
\hline $\begin{array}{l}\mathrm{C}=\mathrm{O} \text { stretching } \\
\text { vibrations }\end{array}$ & $1731 \mathrm{~cm}^{-1}$ & $\mathrm{C}=0$ stretching vibrations & $1747 \mathrm{~cm}^{-1}$ \\
\hline $\mathrm{CH}_{3}$ Bending vibrations & $2950 \mathrm{~cm}^{-1}$ & $\mathrm{CH}_{3}$ Bending vibrations & $2926 \mathrm{~cm}^{-1}$ \\
\hline $\mathrm{CH}_{3}$ stretching vibrations & $1433 \mathrm{~cm}^{-1}$ & $\mathrm{CH}_{3}$ stretching vibrations & $1454 \mathrm{~cm}^{-1}$ \\
\hline $\begin{array}{l}\text { Symmetric and } \\
\text { asymmetric stretching } \\
\text { vibrations of C-O }\end{array}$ & $\begin{array}{l}1143 \mathrm{~cm}^{-1} \text { and } \\
238 \mathrm{~cm}^{-1}\end{array}$ & $\begin{array}{l}\text { Symmetric and } \\
\text { asymmetric stretching } \\
\text { vibrations of C-O }\end{array}$ & $\begin{array}{l}1080 \mathrm{~cm}^{-1} \text { and } \\
1180 \mathrm{~cm}^{-1}\end{array}$ \\
\hline
\end{tabular}

By comparing each polymer nanocomposites (Figure 5(b) and Figure 6(b)) with the blend nanocomposites (Figure 5(c) and Figure 6(c)), a very interesting note was found. When PLA/PMMA blend contained only $1 \mathrm{phr}$ of graphene, its infrared spectrum appeared very similar to the spectrum of PMMA/GNP. For example, the stretching and bending absorption peaks of methyl group in $1433 \mathrm{~cm}^{-1}$ and $2950 \mathrm{~cm}^{-1}$ and the appeared peaks in $1238 \mathrm{~cm}^{-1}$ and $1143 \mathrm{~cm}^{-1}$ related to symmetric and asymmetric $\mathrm{C}-\mathrm{O}$ group which exactly appeared at the same wave number. The peak of carbonyl group in Blend3/GNP1 had also a significantly near to the carbonyl peak of PMMA/GNP. When loading of graphene increased to $3 \mathrm{phr}$, infrared spectrum of Blend3/GNP3 appeared very close to PLA/GNP. For example, appeared peaks in $1454 \mathrm{~cm}^{-1}$ related to the stretching movements of methyl group and appeared peaks in $1129 \mathrm{~cm}^{-1}$ and $1041 \mathrm{~cm}^{-1}$ and $1180 \mathrm{~cm}^{-1}$ related to the carbonyl group showed a remarkable similarity between two spectrums of Blend3/GNP3 and PLA/GNP.

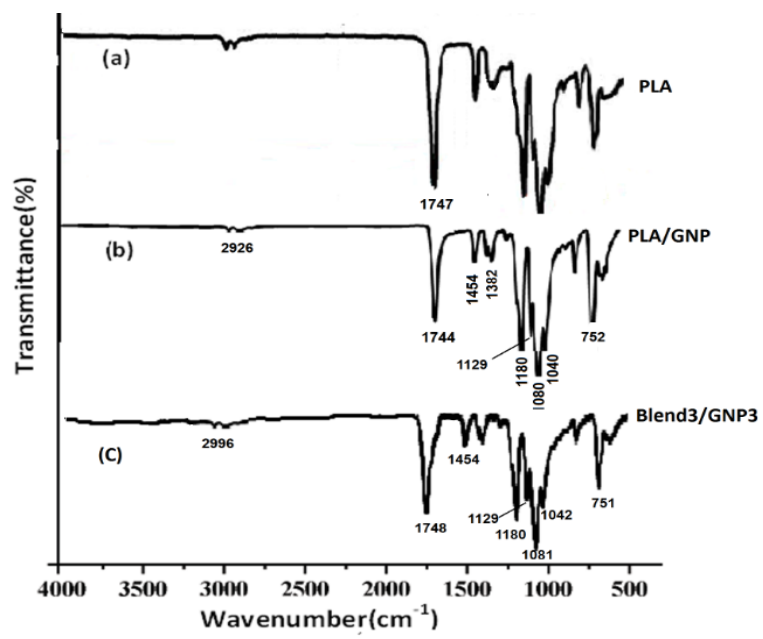

Figure 6: FTIR spectra of PLA in comparison with nanocomposites and blend nanocomposite

The results showed that when the amount of graphene in PLA/PPMA was 1phr, graphene had greater tendency to localize in PMMA phase as approved the results of SEM showing the enlargement of PMMA droplets. When the loading of graphene increased to $3 \mathrm{phr}$ in blends, some of GNP were located in PLA phase which was understand form interaction between GNP and both phases in the FTIR spectra and reduction of the size of dispersed droplets in SEM observations.. In fact, when the amount of graphene increased to $3 \mathrm{phr}$, because localization of some of them in the matrix phase and among droplets, prevent coalescence of the dispersed phase and as a result, showed finer morphology and the compatiblizing effect between the two phases.

\subsection{Mechanical properties}


Tensile test was uswd to evaluate the effect of different amounts of graphene on the mechanical properties of PLA/PMMA blends. The results of this test are given in Figures 7, 8 and 9 for tensile strength, tensile modulus and elongation at break, respectively.

According to Figure 7, increase of the tensile strength in all samples by adding $1 \mathrm{phr}$ and $3 \mathrm{phr}$ grapheme observed indicating effective presence and adhesion of GNP into the blends. It is notable that when the amount of graphene increased to $3 \mathrm{phr}$, the tensile strength of samples increased which can be resulted from the presence of more amounts of GNP in matrix and further strengthens for the matrix of the mentioned blend.

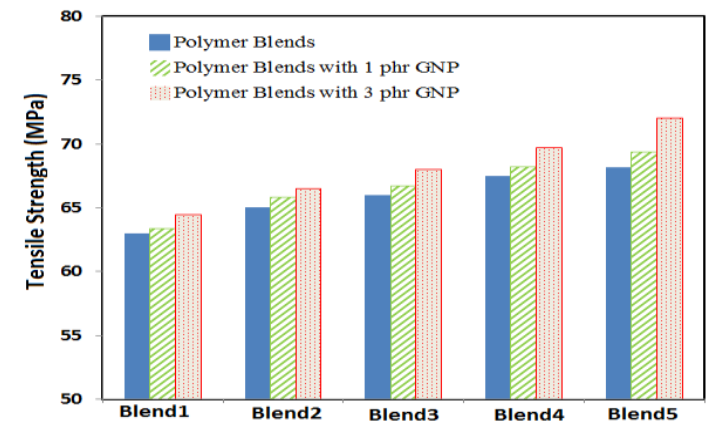

Figure 7: Tensile strength of blend nanocomposite samples in different composition

In Figure 8, the modulus of PLA/PMMA has been traced in comparison with blends containing $1 \mathrm{phr}$ and $3 \mathrm{phr}$ grapheme. Similarly to the strength of samples, in samples containing GNP, the modulus has been increased. But, when the amount of graphene was increased from 1 phr to $3 \mathrm{phr}$, the rate of increase in modulus suddenly enhanced indicating localization a greater amount of GNP in the matrix. These results confirmed the morphology observations and the FTIR results. It is worth noting that by increasing the amount of graphene, the strength increasing of the samples was not significant in comparison with the improvements of the module. The reason can be stated as when the graphene increased to $3 \mathrm{phr}$, despite the presence of much more amount of graphene in the matrix that should lead to a large increase in strength, the formation of graphene aggregates, on the other hand, caused strength decreasing in higher loading of graphene. However, the outcome of these two factors led to an increase in the strength of blend containing $3 \mathrm{phr}$ compared to the blend containing $1 \mathrm{phr}$, the increase was less than the expected amount.

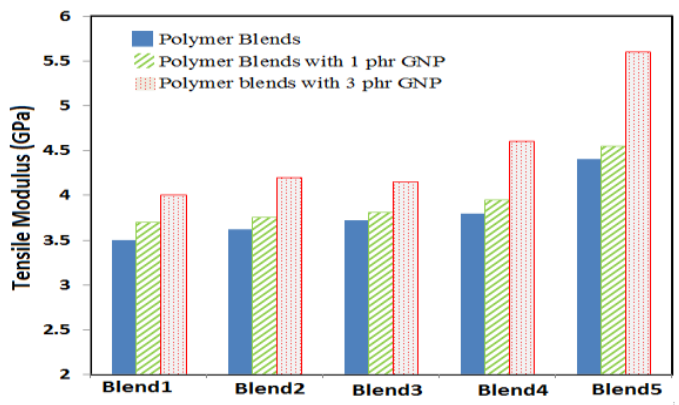

Figure 8: Tensile modulus of blend nanocomposite samples in different composition

Values of elongation at the break of all samples are shown in Figure 9. It is obvious that by adding $1 \mathrm{phr}$ graphene, the elongation at the break of all samples drastically reduces because of the localization of a almost of graphene in the droplets of PMMA, caused stability of droplets and prevention of deformation of droplets. When graphene increased to $3 \mathrm{phr}$, despite the fact that the elongation at the break of all samples was less than samples without graphene, it was higher than samples with $1 \mathrm{phr}$ graphene. This behavior can be caused by the less presence of graphene in the droplets of dispersed phase and more distribution in PLA matrix.

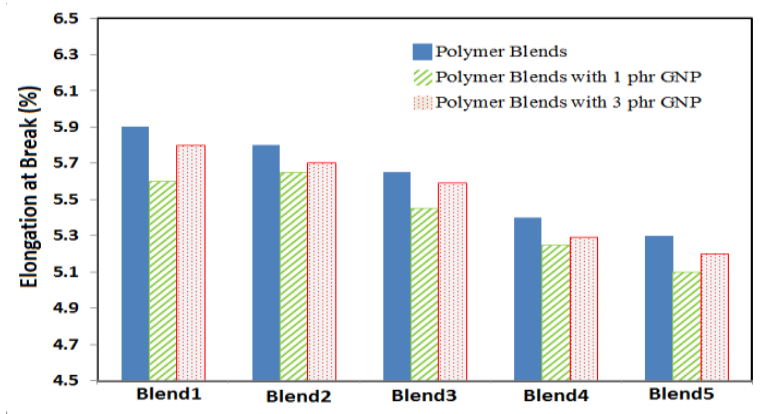

Figure 9: Elongation at break of blend nanocomposite samples in different composition

\subsection{Thermal stability}

In Figure 10, the thermal gravimetric analysis curves of graphene without grapheme (Blend3/GNP0) has been shown compared to 
blends containing graphene (Blend3/GNP1 and Blend3/GNP3).

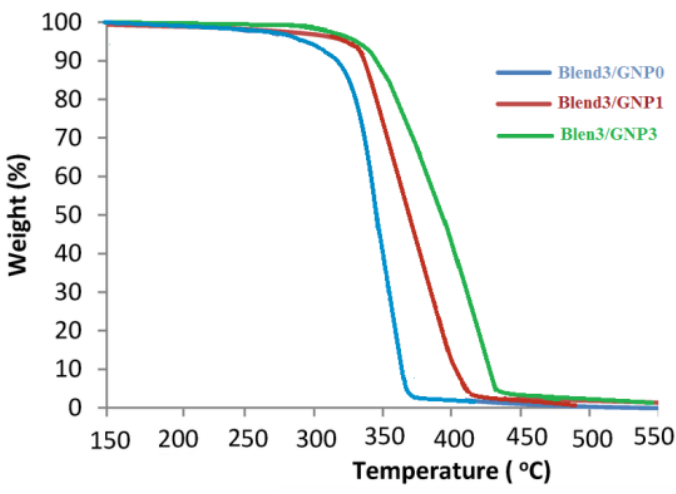

Figure 10: TGA curve of blend samples of PLA/PMMA with the various amounts of graphene

The starting temperature of thermal degradation (Tonset) has been considered since the weight loss of $5 \%$ of sample. Results of TAG showed an improvement in the thermal stability of the blends by adding graphene that can be caused by more thermal stability of graphene in comparison with polymer phases, high thermal conductivity of graphene nanoplatelets as well as the interaction between graphene and polymer phases which lead to more uniform development and increase of thermal conductivity. Moreover, according Table 3, the inflection points of diagrams (the maximum points of derivative of curves) representing the maximum weight loss of samples has appeared at higher temperatures for the GNP filled samples.

Table 3: The effect of different amounts of graphene on the temperature of thermal decomposition in PLA / PMMA

\begin{tabular}{|l|l|l|l|}
\hline Sample code & $\mathrm{T}_{5} \%\left({ }^{\circ} \mathrm{C}\right)$ & $\mathrm{T}_{50} \%\left({ }^{\circ} \mathrm{C}\right)$ & $\mathrm{T}_{100 \%}\left({ }^{\circ} \mathrm{C}\right)$ \\
\hline Blend3/GNP0 & 310.5 & 352.8 & 371.2 \\
\hline Blend3/GNP1 & 325 & 368.4 & 408.3 \\
\hline Blend3/GNP3 & 327.1 & 404.3 & 420.6 \\
\hline
\end{tabular}

\section{Conclusions}

In this study, PLA/PMMA blends with different loading of GNP were prepared by solution casting method and their morphology and properties investigated. According to SEM images, it was determined that adding graphene caused the change in the morphology of the blends. When $1 \mathrm{phr}$ of graphene was added, GNP mainly located in PMMA phase and caused the stability and enlarging the droplets of PMMA. When the amount of graphene reached to $3 \mathrm{phr}$, graphene was located in both phases and since some was in the matrix, it prevented the coalescence of droplets of dispersed phase and as a result, the size and shape of PMMA areas became smaller and more uniform. The results from FTIR also confirmed the interaction between graphene and polymeric phases.

The results of tensile test showed improvement of strength and modulus and reduction in elongation at break of all blends containing graphene, but that amount of change in the properties of GNP filled blends dependent to the localization of graphene into polymer phases. The results of Thermal Gravimetric Analysis (TGA) of samples indicated the significant improvement of thermal stability in the blends containing graphene.

\section{References}

Allen, M. J.; Tung, V. C.; Kaner, R. B. (2009), Honeycomb carbon: a review of graphene. Chem. Rev. 110, 132-145.

Anderson, K. S.; Schreck, K. M.; Hillmyer, M. A. (2008), Toughening polylactide. Polym. Rev. $48,85-108$.

Balakrishnan, H.; Hassan, A.; Imran, M.; Wahit, M. U. (2012), Toughening of polylactic acid nanocomposites: A short review. Polym. Plast. Technol. Eng. 51, 175-192.

Cao, Y.; Zhang, J.; Feng, J.; Wu, P. (2011), Compatibilization of immiscible polymer blends using graphene oxide sheets. ACS Nano. 5, 5920-5927.

Du, J.; Cheng, H. M. (2012), the fabrication, properties, and uses of graphene/polymer composites. Macromol. Chem. Phys. 213, 1060-1077.

Fu, Y.; Liao, L.; Yang, L.; Lan, Y.; Mei, L.; Liu, Y.; $\mathrm{Hu}$, S. (2013), Molecular dynamics and dissipative particle dynamics simulations for prediction of miscibility in polyethylene terephthalate/polylactide blends. Mol. Simulat. 39, 415-422.

Gui, Z.; Zhang, W.; Lu, C.; Cheng, S. (2013), Improving the barrier properties of poly (lactic acid) by blending with poly (ethylene- 
co-vinyl alcohol). J. Macromol. Sci., Part B, Phys. 52, 685-700.

Henton, D. E.; Gruber, P.; Lunt, J.; Randall, (2005), J. Polylactic acid technology. In Natural Fibers, Biopolymers, and Biocomposites; Mohanty, A. K.; Misra, M.; Drzal, L. T.; Boca Raton: CRC Press, 527-577.

Jancar, J.; Fekete, E. (1999), Mineral fillers in thermoplastics I: raw materials and processing (Vol. 139). Berlin:Springer Science \& Business Media, Chap.3.

Jung, I.; Ha, C. S.; Cho, Y.; Yoo, S.; Lee, W. K. (2014), Solvent-Induced Surface Structure of Poly (vinylidene fluoride)/Biodegradable Polyester Blend Films. Mol. Cryst. Liq. Cryst. 598, 23-27.

Liebscher, M.; Blais, M. O.; Pötschke, P.; Heinrich, G. (2013), A morphological study on the dispersion and selective localization behavior of graphene nanoplatelets in immiscible polymer blends of PC and SAN. Polymer. 54, 5875-5882.

Mittal, V., (2012), Functional polymer blends: synthesis, properties, and performance. Boca Raton: CRC Press, Chap. 2.

Mittal, V.; Luckachan, G. E.; Matsko, N. B. (2014), $\mathrm{PE} /$ Chlorinated-PE Blends and PE/Chlorinated-PE/Graphene Oxide Nanocomposites: Morphology, Phase Miscibility, and Interfacial Interactions. Macromol. Chem. Phys. 215, 255-268.

Mohamadi, S.; Sharifi-Sanjani, N. (2011), Investigation of the crystalline structure of PVDF in PVDF/PMMA/graphene polymer blend nanocomposites. Polym. Compos. 32, 1451-1460.

Neto, A. C.; Guinea, F.; Peres, N. M. R.; Novoselov, K. S.; Geim, A. K. (2009), The electronic properties of graphene. Rev. Mod. Phys. 81, 109.

Pötschke, P.; Göldel, A.; Gültner, M.; Liebscher, M. Lcalization Behavior of Carbon nanotubes and Graphene nanoplatelets in Melt-Mixed Immiscible Polymer Blends, paper presented at POLYCHAR 22 World Forum on Advanced Materials, Stellenbosch, April (2014).
Paul, D. R., Bucknall, C. B, (2000), Polymer blends; Wiley-Interscience: New York, Chap. 2

Teamsinsungvon, A.; Ruksakulpiwat, Y.; Jarukumjorn, K. (2013), Preparation and Characterization of Poly (lactic acid)/Poly (butylene adipate-co-terepthalate) Blends and Their Composite. Polym. Plast. Technol. Eng. 52, 1362-1367.

Terrones, M.; Martín, O.; González, M.; Pozuelo, J.; Serrano, B.; Cabanelas, J. C. (2011), Interphases in Graphene Polymer-based Nanocomposites: Achievements and Challenges. Adv. Mater. 23, 5302-5310.

Yang, J.; Feng, C.; Dai, J.; Zhang, N.; Huang, T.; Wang, Y. (2013), Compatibilization of immiscible nylon 6/poly (vinylidene fluoride) blends using graphene oxides. Polym. Int. 62, 1085-1093.

Yuan, H.; Liu, Z.; Ren, 49, (2009), Preparation, characterization, and foaming behavior of poly (lactic acid)/poly (butylene adipate-co-butylene terephthalate) blend. Polym. Eng. Sci. 1004-1012.

Zhang, G.; Zhang, J.; Wang, S.; Shen, D. (2003), Miscibility and phase structure of binary blends of polylactide and poly (methyl methacrylate). J. Polym. Sci., Part B: Polym. Phys. 41, 23-30. 